\title{
The promotion and inhibition of chromium and kinetic analysis on the growth of Platymonas Helgolandica
}

\author{
Lijing Bai ${ }^{1}$, Zhaosong $\mathrm{Li}^{2}$ \\ ${ }^{1}$ School of Environmental Science and Engineering, Qingdao University, Qingdao, China \\ ${ }^{2}$ School of Mechanical and Electronic Engineering, Shandong University of Science and Technology, \\ Qingdao, China \\ ${ }^{1}$ Corresponding author \\ E-mail: ${ }^{1} 1073149189 @ q q . c o m,{ }^{2} 1071348034 @ q q . c o m$
}

Received 5 May 2018; received in revised form 5 June 2018; accepted 19 June 2018 DOI https://doi.org/10.21595/chs.2018.20010

Check for updates

Copyright $(\mathrm{C} 2018$ Lijing Bai, et al. This is an open access article distributed under the Creative Commons Attribution License, which permits unrestricted use, distribution, and reproduction in any medium, provided the original work is properly cited.

\begin{abstract}
In this work, Platymonas helgolandica was used as an experimental material to study the effect of chromium on it. Under the experimental ecological condition, the concentrations of $\mathrm{Cr}$ (VI) were set as $0,0.05,0.1,1$, and $10 \mathrm{mg} / \mathrm{L}$. Every concentration designed with three parallel groups. The ecotoxicology method was used to investigate the impact of $\mathrm{Cr}$ (VI) on $P$. helgolandica, and $\left(\mathrm{EC}_{50}\right)$ was calculated by the method of linear interpolation. The results showed the growth of $P$. helgolandica had a more obvious "Hormesis" when chromium was $0.05 \mathrm{mg} / \mathrm{L}$. However, with $\mathrm{Cr}$ (VI) increased, the inhibition on $P$. helgolandica was increasing, and the cell density of $P$. helgolandica decreased. The $\mathrm{EC}_{50}$ achieved at $24 \mathrm{~h}, 48 \mathrm{~h}$, and $72 \mathrm{~h}$ revealed that the relative growth rate had a downward trend over time. The remodified Logistic model, the modified Gompertz model, and the Logistic model were suitable to describe cell density in an operating cycle and were beneficial to explore the growth of $P$. helgolandica.
\end{abstract}

Keywords: chromium, Platymonas helgolandica, cell density, relative growth rate, kinetic analysis.

\section{Introduction}

Chromium was an element existed in nature widely. It was mainly displayed in the form of tri-valent chromium $\mathrm{Cr}$ (III) and six-valent chromium $\mathrm{Cr}$ (VI) in water environment. $\mathrm{Cr}$ (VI) was a clear harmful substance. It had carcinogenic and teratogenic effects and was not easy to degrade [1-3]. When the wastewater containing $\mathrm{Cr}$ (VI) was discharged into the water body that had a large number of aquatic plants and aquatic animals, $\mathrm{Cr}$ (VI) could be enriched by the food chain and played a threat to biological health [4].

Platymonas helgolandica belonged to the Chlorophyta, Chlorophyceae, Volvocales, Chlamydomonadaceae, Platymonas, and thrived in warmer and more organic water body. Moreover, Platymonas helgolandica was cultivated at home and abroad widely, eaten by larvae of marine products [5].

The promotion and inhibition of chromium on the growth of the $P$. helgolandica was a prerequisite for exploring the effects of heavy metals on the marine ecosystem, and it was of great significance to investigate the effects of heavy metals on the ocean in future. Therefore, the experiment took $P$. helgolandica as a test object. The impact of $\mathrm{Cr}$ (VI) with different concentration gradient on the growth of $P$. helgolandica was observed. The changes of cell density and relative growth rate of $P$. helgolandica were studied under $\mathrm{Cr}$ (VI) stress, in order to investigate the toxic effect of chromium on it. Besides, the remodified Logistic model, the modified Gompertz model, and the Logistic model were used to describe cell density in an operating cycle and to evaluate the growth of $P$. helgolandica. 


\section{Materials and methods}

\subsection{Experimental algae species and culture conditions}

Experimental algae species was $P$. helgolandica. $\mathrm{Cr}$ (VI) solution was composed of potassium dichromate. The natural seawater from Qingdao was filtered through degreasing cotton, and then boiled $15 \mathrm{~min}$. After cooling, nutrient solution was allocated, and $\mathrm{f} / 2$ nutrients formula was used for culture medium. The light intensity was $3000 \mathrm{~lx}$, rhythmic light was $12 \mathrm{~h}: 12 \mathrm{~h}$, the temperature was $20 \pm 1^{\circ} \mathrm{C}$, and $\mathrm{pH}$ was $8.1-8.2$.

\subsection{Experimental methods}

On the basis of the pre-experiment, $\mathrm{Cr}$ (VI) solution with different concentration gradient was set up. There were four treatment groups and one control group, every processing was repeated three times and the averaged value was reported. During exponential growth cycle, $P$. helgolandica was inoculated and incubated in a constant temperature incubator. After the Lugol reagent was added, the cell density was determined, and the cell density and relative growth rate of cells were calculated by blood counting chamber. In the work, the average number of cell density of mother liquid was $16.79 \times 10^{4} / \mathrm{mL}$, and the inoculation density was $4.20 \times 10^{4} / \mathrm{mL}$.

The blood counting chamber principle diagram and the image under the microscope:
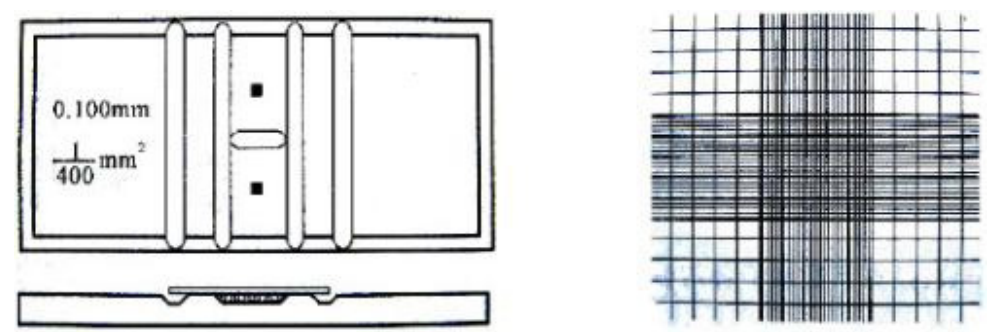

a) The blood count plate diagram and counting area schematic

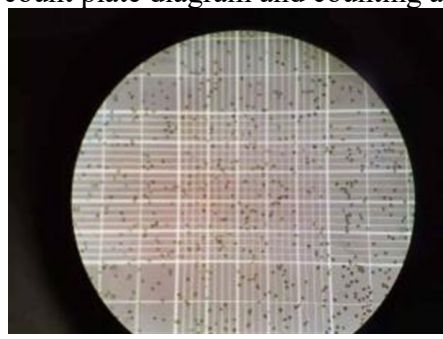

b) $P$. helgolandica image $10 \times$ magnification under the microscope

Fig. 1. The principle diagram and the image displayed by microscope

The number of cells in every milliliter of medium:

$A / m L=a \times 400 \times 10^{4} \times b / c$,

where $A$ is cell number, $a$ is cell number in small square, $b$ is dilution ratio, and $c$ is number of small squares selected.

Relative growth rate of cell [6]:

$K=\left(\lg N_{t}-\lg N_{o}\right) / T$,

where $N_{t}$ is cell density at $t$ time, $\mathrm{mg} / \mathrm{L}, N_{O}$ is cell density at initial density, $\mathrm{mg} / \mathrm{L}, T$ is culture time, $\mathrm{h}$. 


\subsection{Kinetic analysis}

The remodified Logistic model (Eq. (3)), the modified Gompertz model (Eq. (4)), and the Logistic model (Eq. (5)) were suitable to describe cell density of $P$. helgolandica in an operating cycle. The remodified Logistic model was the first to describe hydrogen production process in batch test [7]. The modified Gompertz model could be used to indicate the cell growth and product formation [8]. The Logistic model used to describe microbe growth curve.

The remodified Logistic model:

$$
C D=\frac{C D_{\max }}{1+\exp \left[\frac{4 R_{\max (\lambda-t)}}{C D_{\max }+2}\right]}
$$

The modified Gompertz model:

$C D=C D_{\max } \exp \left[-\exp \left(\frac{R_{\max } e(\lambda-t)}{C D_{\max }}+1\right)\right]$.

The Logistic model:

$C D=C D_{\max }+\frac{C D_{\min }-C D_{\max }}{1+\left(\frac{t}{E C_{50 t}}\right)^{p}}$,

where $C D$ is cell density, $\left(\times 10^{4} / \mathrm{mL}\right) ; C D_{\max }$ is maximum cell density, $\left(\times 10^{4} / \mathrm{mL}\right) ; R_{\max }$ is maximum cell growth efficiency, $\left(\times 10^{4} / \mathrm{mL}\right) / \mathrm{h} ; \lambda$ is lag time, $\mathrm{h} ; t$ is experimental time, $\mathrm{h} ; C D_{\min }$ is minimum cell density, $\left(\times 10^{4} / \mathrm{mL}\right) ; E C_{50 t}$ is time of $50 \%$ maximum cell density, $\mathrm{h} ; p$ is exponent.

\section{Experimental results and analysis}

\subsection{The effect of chromium on the growth of $P$. helgolandica}

The effect of different concentrations of $\mathrm{Cr}$ (VI) among $72 \mathrm{~h}$ on cell density of $P$. helgolandica was shown in Fig. 2.

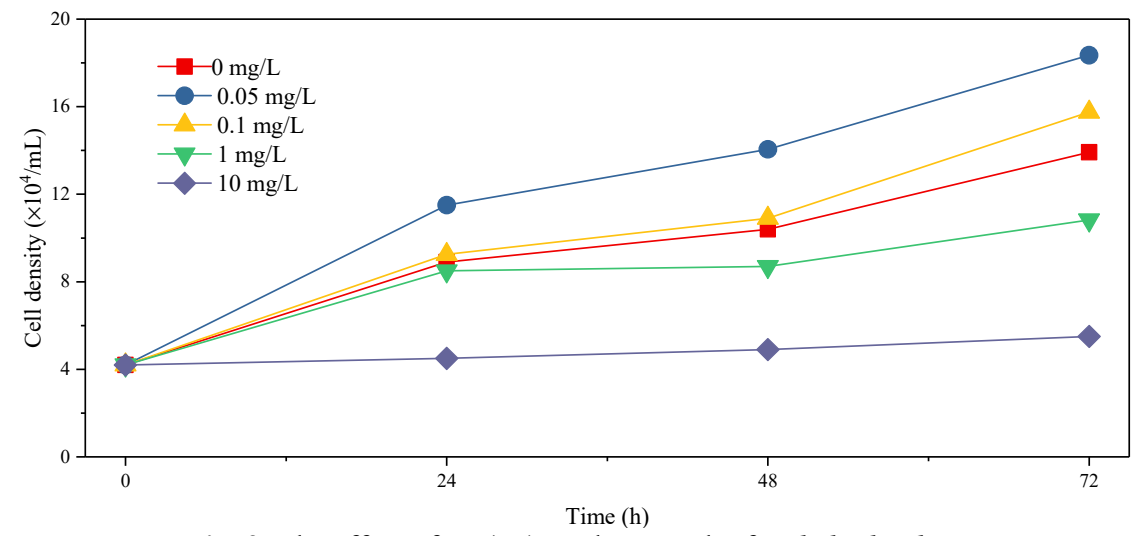

Fig. 2. The effect of $\mathrm{Cr}(\mathrm{VI})$ on the growth of $P$. helgolandica

It was known from Fig. 2 that the growth of $P$. helgolandica showed a more obvious "Hormesis" and cell density increased at low concentration of chromium. This effect was strongest 
when the concentration of $\mathrm{Cr}$ (VI) was $0.05 \mathrm{mg} / \mathrm{L}$. However, when the concentration of chromium exceeded $0.1 \mathrm{mg} / \mathrm{L}$, the inhibition would present, and even threaten survival of $P$. helgolandica.

\subsection{The effect of chromium on the relative growth rate of $P$. helgolandica}

\subsubsection{The effect of chromium on the relative growth rate of $P$. helgolandica in $24 \mathrm{~h}$.}

Fig. 3 revealed that the relative growth of $P$. helgolandica increased first and then decreased with the increase of chromium concentration. When the chromium concentration was $0.05 \mathrm{mg} / \mathrm{L}$, the relative growth rate of $P$. helgolandica was the highest and $\mathrm{Cr}(\mathrm{VI})$ has a significant impact on the growth of $P$. helgolandica. With the continuous increase of chromium concentration, the promotion weakened gradually and showed inhibitory effect. From the change of $K$ value, it could be concluded that the $24 \mathrm{~h}-\mathrm{EC}_{50}$ of chromium to $P$. helgolandica was $5.18 \mathrm{mg} / \mathrm{L}$.

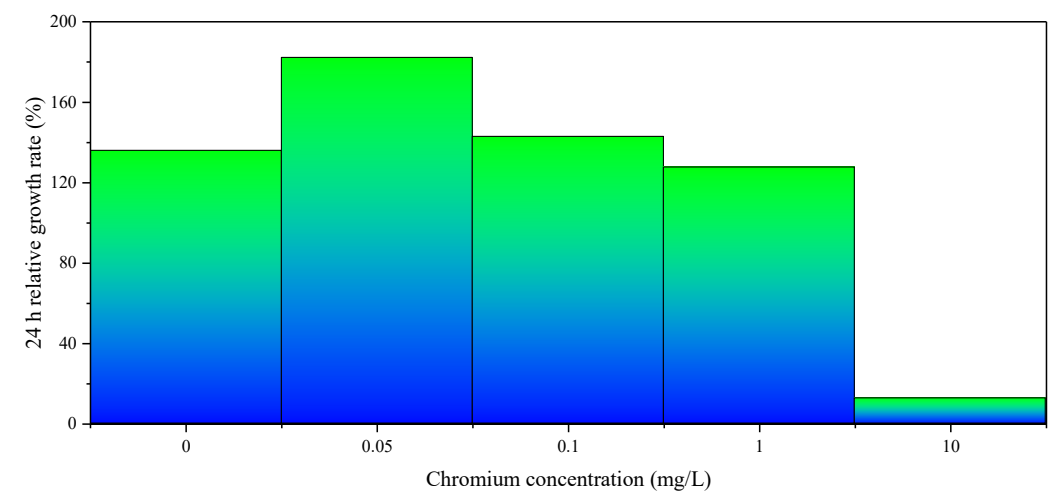

Fig. 3. The effect of chromium on the relative growth rate of $P$. helgolandica in $24 \mathrm{~h}$

\subsubsection{The effect of chromium on the relative growth rate of $P$. helgolandica in $48 \mathrm{~h}$}

It was known from Fig. 4 that the relative growth rate of P.helgolandica showed a tendency to increase first and then decreased. When $\mathrm{Cr}(\mathrm{VI})$ concentration was $0.05 \mathrm{mg} / \mathrm{L}$, the relative growth rate of $P$. helgolandica was the largest, which was $109.30 \%$, and chromium had an obvious promoting effect on the growth of $P$. helgolandica. With the continuous increase of chromium concentration, this "excitatory effect" weakened gradually and showed inhibitory effect. When chromium concentration was $10 \mathrm{mg} / \mathrm{L}$, the relative growth rate of $P$. helgolandica was $13.90 \%$. From the change of $K$ value, it could be concluded that the $48 \mathrm{~h}-\mathrm{EC}_{50}$ of chromium to $P$. helgolandica was $4.09 \mathrm{mg} / \mathrm{L}$.

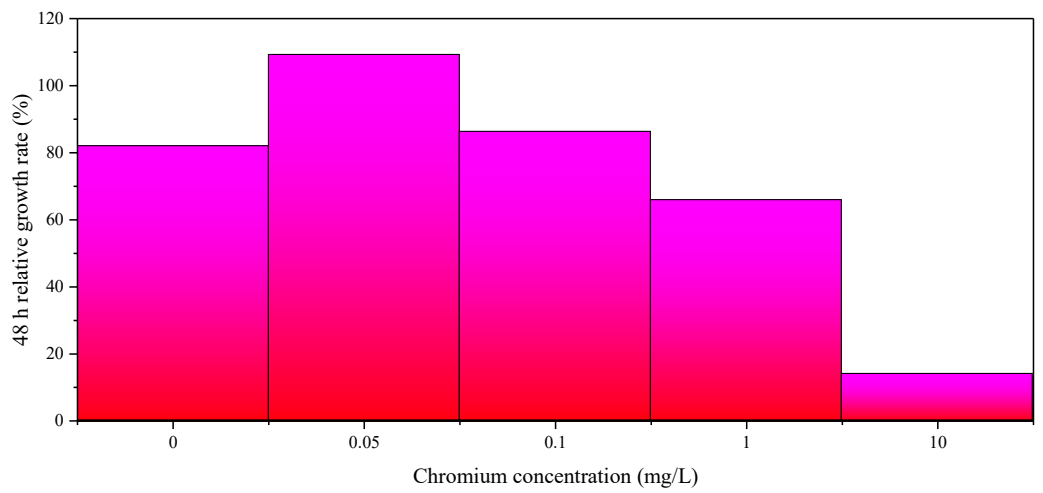

Fig. 4. The effect of chromium on the relative growth rate of $P$. helgolandica in $48 \mathrm{~h}$ 


\subsubsection{The effect of chromium on the relative growth rate of $P$. helgolandica in $72 \mathrm{~h}$}

Fig. 5 displayed that the relative growth of $P$. helgolandica increased first and then decreased with increasing chromium concentration. When the $\mathrm{Cr}$ (VI) concentration was $0.05 \mathrm{mg} / \mathrm{L}$, the relative growth rate of $P$. helgolandica was $88.90 \%$, and chromium has obvious promotion on the growth of $P$. helgolandica. When chromium concentration was $0.1 \mathrm{mg} / \mathrm{L}$, it also had "excitatory effect". With the increasing of chromium concentration, this promotion weakened gradually and showed inhibitory effect. From the change of $K$ value, it can be concluded that the $72 \mathrm{~h}-\mathrm{EC}_{50}$ of chromium to $P$. helgolandica was $3.82 \mathrm{mg} / \mathrm{L}$.

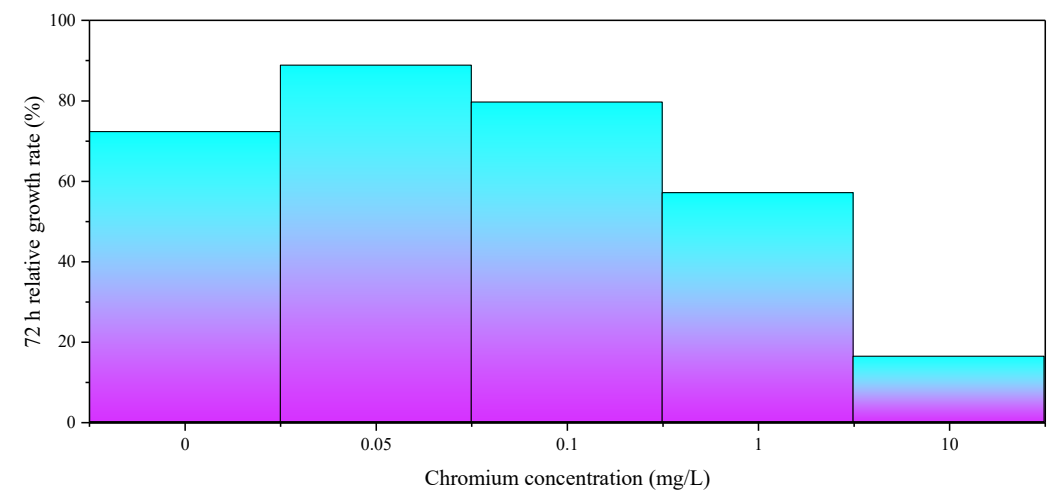

Fig. 5. The effect of chromium on the relative growth rate of $P$. helgolandica in $72 \mathrm{~h}$

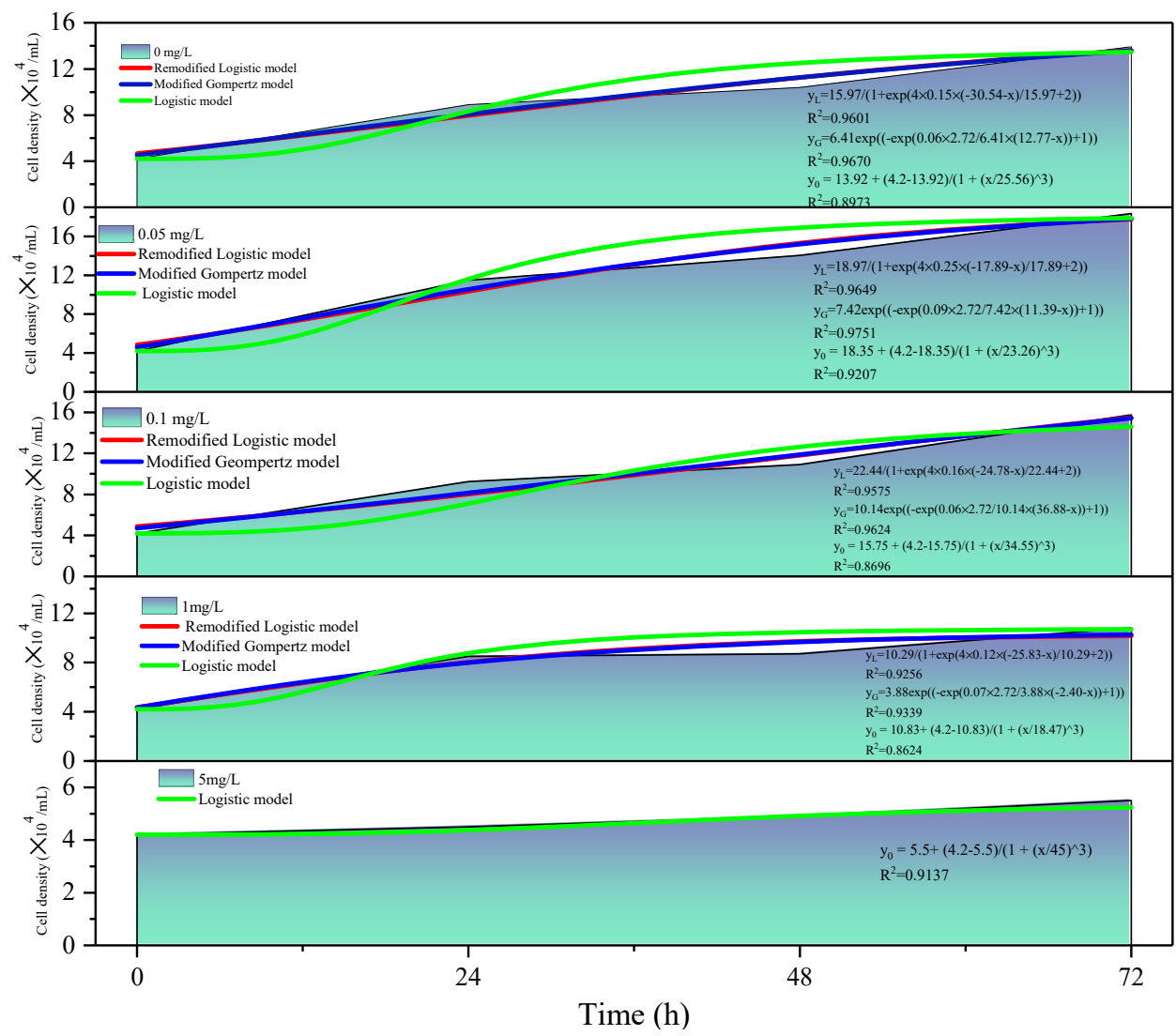

Fig. 6. Kinetic analysis to cell density of $P$. helgolandica among $72 \mathrm{~h}$ was shown in Fig. 6 


\subsection{Kinetic analysis about cell density of $P$. helgolandica in an operation cycle}

The effect of $\mathrm{Cr}(\mathrm{VI})$ on cell density of $P$. helgolandica among $72 \mathrm{~h}$ was shown in Fig. 6.

The cell density and kinetic features with $\mathrm{Cr}(\mathrm{VI})$ addition in an operating cycle were described by the remodified Logistic model (Eq. (3)), the modified Gompertz model (Eq. (4)) and the Logistic model (Eq. (5)). Kinetic parameters and fitting formulas were showed in Fig. 6.

Compared the parameters were obtained by three models, which all had relatively higher correlation coefficients $\left(\mathrm{R}^{2}\right)$. It can be obtained by multiple fitting, and the remodified Logistic model and the modified Gompertz model were suiting to describe the changes of $P$. helgolandica of cell density at $0,0.05,0.1$, and $1 \mathrm{mg} / \mathrm{L}$. The Logistic model could describe all $\mathrm{Cr}(\mathrm{VI})$ concentrations cell density variation.

\section{Discussion}

\subsection{The discussion of the effect of chromium on the growth of $P$. helgolandica}

From the effects on cell density of $P$. helgolandica at different Cr (VI) concentrations, chromium showed a "low promotion and high inhibition" on the growth of $P$. helgolandica. At low concentrations of $0.05 \mathrm{mg} / \mathrm{L}$ and $0.1 \mathrm{mg} / \mathrm{L}$, it showed a significant promotion effect compared with the control group. This phenomenon also occurred in previous studies on the toxic effect of heavy metals copper and cadmium on green algae [9]. Algae exhibited stress resistance and stimulate algal growth when disturbed by weak stresses may be a main reason. Many low concentration promotion phenomena had also been observed in some published articles [10, 11]. It indicated that the "excitatory effect" of marine microalgae caused by low concentration of heavy metals was universal.

When the $P$. helgolandica was treated with high $\mathrm{Cr}(\mathrm{VI})$ concentration showed inhibitory effect. When the chromium concentration was $1 \mathrm{mg} / \mathrm{L}$, the inhibition began to be showed. With the increase of $\mathrm{Cr}$ (VI) concentration, the inhibition was more obvious. The cause of this phenomenon was that chromium destroyed the cell structure of $P$. helgolandica and destroyed its superoxide dismutase activity and the content of photosynthetic pigment, which affected photosynthesis and inhibited growth and reproduction.

\subsection{The discussion of the effect of chromium on the relative growth rate of $P$. helgolandica}

From Fig. 3, Fig. 4, and Fig. 5, it was found that when $\mathrm{Cr}$ (VI) concentration were 0, 0.05, 0.1, 1 , and $10 \mathrm{mg} / \mathrm{L}$, all were in the tolerance range of $P$. helgolandica.

$\mathrm{EC}_{50}$ was an important parameter to measure the biological toxicity of toxic substances in water, and $\mathrm{EC}_{50}$ was related to the time of exposure to toxic environment [12]. $24 \mathrm{~h}-\mathrm{EC}_{50}$, $48 \mathrm{~h}-\mathrm{EC}_{50}$, and $72 \mathrm{~h}-\mathrm{EC}_{50}$ were $5.18,4.09$, and $3.82 \mathrm{mg} / \mathrm{L}$, respectively. It was known that with the extended of contact time between $P$. helgolandica and chromium, the greater degree of damage to $P$. helgolandica.

The relative growth rate of $24 \mathrm{~h}$, the relative growth rate of $48 \mathrm{~h}$, and the relative growth rate of $72 \mathrm{~h}$ gradual declined. The cause of this phenomenon may be that the relative growth rate of $P$. helgolandica was affected by the exposure time, and the longer the exposure time of $P$. helgolandica in the toxic environment, the more bad impact. It may also be due to the growth and reproduction of $P$. helgolandica depleted part of the nutrient in the culture solution resulting in the lack of nutrients, which limited $P$. helgolandica growth and reproduction

\subsection{The discussion about kinetic feature of $P$. helgolandica in an operation cycle}

Parameters were compared obtained by three models that the remodified Logistic model (Eq. (3)), the modified Gompertz model (Eq. (4)), and the Logistic model (Eq. (5)). The modified Gompertz model owned best $R^{2}$ was 0.9596 , above 0.9520 and 0.8927 provided respectively by 
the remodified Logistic model and the Logistic model. However, the $C D_{\max }$ presented by the first two models were discrepant. Comparing the differences between the experimental and the predicted values, average relative error respectively are $16.37 \%$ and $37.31 \%$. Average relative error of the remodified Logistic model was only $3.38 \%$ in $0.05 \mathrm{mg} / \mathrm{L}$, and the modified Gompertz model was little more than $0.09 \%$ in $1 \mathrm{mg} / \mathrm{L}$. Suitable models were good at predicting cell density at different chromium concentrations.

The Logistic model could match all the concentration of the cell density change trend, and be able to provide the time of appearance $20 \%, 50 \%$, and $80 \%$ maximum cell density, predict cell density at different times. In addition, other kinetic parameters $\left(\lambda, C D_{\min }\right)$ could also be deduced well by three models. In order to maximum enhancement for $P$. helgolandica $\mathrm{Cr}$ (VI) dosage had best controlled at $0.05 \mathrm{mg} / \mathrm{L}$.

\section{Conclusion}

The effect of chromium on the growth of $P$. helgolandica was studied in the work. When the chromium concentrations were $0.5 \mathrm{mg} / \mathrm{L}$ and $0.1 \mathrm{mg} / \mathrm{L}$, the growth of $P$. helgolandica showed a more obvious "excitatory effect". However, when the chromium concentration exceeded to $1 \mathrm{mg} / \mathrm{L}$, the inhibition appeared, and the cell density of $P$. helgolandica descend. Compared with the $\mathrm{EC}_{50}$ at $24 \mathrm{~h}, 48 \mathrm{~h}$, and $72 \mathrm{~h}$, it was discovered that the relative growth rate of $P$. helgolandica decreased with the extension of time. The remodified Logistic model and the modified Gompertz model were suitable for predicting $C D_{\max }$, and the Logistic model be able to provide the time of appearance $20 \%, 50 \%$ and $80 \%$ maximum cell density.

\section{References}

[1] Yan W., Qunwei D., Guohua C. Cr (VI) adsorption characteristic of alga adsorbent. Journal of Environmental Engineering, Vol. 5, Issue 8, 2014, p. 2006-2010.

[2] Xianlong Z., Siyang Z., Jingwei F. Preparation of nano-iron for removing Cr (VI) from wastewaters. Chinese Journal of Environmental Engineering, Vol. 9, Issue 6, 2012, p. 3167-3172.

[3] Ying L., Chunqiang L., Chuanyuan T. Effects of different nutrient concentrations on the succession of 6 Marine microalgae communities. Aquatic Science, Vol. 32, Issue 11, 2013, p. 627-635.

[4] Jinhua Y. Effects of anthracene on the growth of Platymonas helgolandica. Science and Technology Information, Vol. 28, Issue 6, 2011, p. 345-345.

[5] Xiaogang H., Tinglin H., Xiuzhen C. Study on the application of ferrous sulfate reduction-precipitation method to the emergent treatment of sudden $\mathrm{Cr}$ (VI) pollution. Industrial Water Treatment, Vol. 33, Issue 6, 2013, p. 40-46.

[6] Shuai M., Liang Q., Xiaogong L. Effects of four dispersants on cell density and chlorophyll contents of Platymonas helgolandica and Nitzschia closterium f. minutissima. Ecological Science, Vol. 34, Issue 6, 2015, p. 9-15.

[7] Zhong W., Yongzhen P., Lei M. Continuous-flow combined process of nitritation and ANAMMOX for treatment of landfill leachate. Bioresource Technology, Vol. 214, 2016, p. 514-519.

[8] Jianlong W., Wei W. Kinetic models for fermentative hydrogen production: a review. International Journal of Hydrogen Energy, Vol. 34, Issue 8, 2009, p. 3313-3323.

[9] Hongwei H., Yuanyuan D., Yunfei F. Effects of artificial sweeteners on metal bioconcentration and toxicity on a green algae Scenedesmus obliquus. Chemosphere, Vol. 150, 2016, p. 285-293.

[10] Qiongzhi Z., Feng L., Feng G. Nutrient removal by Chlorella vulgaris F1068 under cetyltrimethyl ammonium bromide induced hormesis. Environmental Science and Pollution Research, Vol.23, Issue 19, 2016, p. 1-11.

[11] Jiashun C., Ruixue J., Jiaqin W. Study on the interaction mechanism between cefradine and Chlamydomonas reinhardtii in water solutions under dark condition. Ecotoxicology and Environmental Safety, Vol. 159, 2018, p. 56-62.

[12] Tennekes H A., Sánchez-Bayo F. The molecular basis of simple relationships between exposure concentration and toxic effects with time. Toxicology, Vol. 309, Issue 2, 2013, p. 39-51. 